\title{
Intergenerational persistence of family formation trajectories among teenage-mothers and -fathers in Sweden
}

\section{Sara Kalucza $^{1}$ (D) $\cdot$ Sergi Vidal $^{2} \cdot$ Karina Nilsson $^{1}$}

Accepted: 20 May 2021 / Published online: 2 June 2021

(c) The Author(s) 2021

\begin{abstract}
In this paper, we address the questions of whether early family trajectories of parents are reflected in childbearing teenagers, and how socio-economic and family background factors impact these intergenerational correlations. We use within-dyad sequence analysis to examine combined marital and childbearing trajectories, up to age 30, of two generations of a representative sample of childbearing teenagers born between 1975 and 1985 and their progenitors, drawn from the Swedish population register data. We find evidence for within-family persistence of early family trajectories, with better matches across family state sequences for dyads composed of childbearing teenagers and their parents, than for dyads composed of childbearing teenagers and parents of random birth cohort peers. Regression analysis shows that these intergenerational associations are stronger and occur among later-born siblings from non-traditional family backgrounds, and among families with lower socio-economic backgrounds. This study fills gaps in the knowledge of intergenerational family life course dynamics beyond the early parenthood event.
\end{abstract}

Keywords Teenage parenthood $\cdot$ Adolescent fertility $\cdot$ Intergenerational transmission $\cdot$ Sequence analysis $\cdot$ Sweden

Sara Kalucza

sara.kalucza@umu.se

Sergi Vidal

svidal@ced.uab.es

Karina Nilsson

karina.nilsson@umu.se

1 Department of Sociology, Umeå University, Umeå, Sweden

2 Centre for Demographic Studies, Universitat Autonoma de Barcelona, Bellaterra, Spain 


\section{Introduction}

The connection between teenage fertility and family background is well known, and specifically the connection between women's first birth during teenage years and own mother's young age at first birth, known as intergenerational reproduction of teenage childbearing, has been established in many previous studies across countries, including Sweden (e.g. Barber 2001; Meade et al. 2008; Sipsma et al. 2010; Stanfors and Scott 2013; Steenhof and Liefbroer 2008; Wall-Wieler et al. 2016).

While this intergenerational association is undisputed, little is known on whether teenage parents also follow the long-term family trajectories of their own parents. Teenage motherhood is known to be associated with specific continued family events and behaviour, such as rapid repeat pregnancies (Reese and Halpern 2017), high total fertility (Olausson 2001) and low rates of marriage (Manning and Cohen 2015; Oberlander et al. 2010). In this study we investigate these long-term correlations between the family life courses of parents and children, both mothers and fathers of two generations, given that there are two reasons to expect a substantive intergenerational correlation of family life courses.

First, the family trajectories of teenage parents do not follow societally defined scripts. Previous research has shown that key role transitions in the passage from adolescence to adulthood, including becoming a parent, are tied to social and cultural norms about age (timing) and order (sequence) (Elder 1998; Rook et al. 1989). Teenage parenthood is deemed to occur off time (Neugarten 1979; Billari et al. 2011) in contemporary societies, where age at first birth has been increasing for decades (OECD 2016a). In addition, an early birth often occurs before acquiring a formal education credential, which is out of the normative sequence (Elder 1998). Under such normative vacuum, teenage parents could be more likely to use their own parents' family trajectories as models than the socially defined models from which they have initially departed. Arguably, parents may offer support and approval for children's non-normative trajectories that they followed themselves.

Second, teenage parenthood is a marker for general disadvantage over the life course, and its reproduction across generations. Off-time life course events (such as teenage childbearing) are often subject to social sanctions that feed further out-of-the-norm behaviours and accumulation of disadvantage among sanctioned individuals (Dannefer et al. 2016). Along these lines, research finds that typical outcomes among teenage parents include low educational attainment, low earnings capacity, unstable employment and enduring welfare dependence over the life course (Assini-Meytin and Green 2015; Buchmann and Kriesi 2011). In addition, empirical research has mostly attributed the source of these outcomes to the family background of teenage parents-who are frequently concentrated in disadvantaged contexts, suggesting that teenage parenthood per se plays a smaller role (e.g., Fletcher and Wolfe 2009; Lee 2010; Webbink et al. 2011). Nonetheless, previous studies show that teenage parents have an increased likelihood of replicating socio-economic disadvantage across generations, from their own parents on to the next generation and their own children (Cunnington 2001; Furstenberg 
1991; Geronimus and Korenman 1993; SmithBattle 2007). Given that teenage parenthood is reproduced in backgrounds and contexts of disadvantage, we could also expect that these underlying disadvantages in the family of origin impact the dynamics of partnership and childbearing that follow teenage parenthood. We note that is important for policy to address such questions, as family strategies upon teenage parenthood can potentially amplify or alleviate the potential longterm negative impacts of teenage parenthood.

In this paper we contribute new insights on the intergenerational correlations in family-forming behaviours of teenage parents, adopting a long-term life course approach that considers the transmission of broader life processes from parents to children rather than specific point-in-time transitions. Specifically, we examine (i) the correlations of family trajectories between teenage mothers and fathers, and their progenitors and (ii) the antecedents of any observed intergenerational correlations. Our study extends the emerging trajectory-based research on intergenerational linkages in family development on general populations (Liefbroer and Elzinga 2012; Raab et al. 2014; Robette et al., 2015) by focusing on non-normative family patterns and a vulnerable subpopulation. The study, thus, offers an opportunity to expand knowledge on potential mechanisms behind persistent disadvantage related to family dynamics. We also contribute to the literature by examining both men and women from two generations. Thus, we move from a focus on teenage mothers to also consider the role of teenage fathers and the reproduction of the father's family behaviour, a group often unaccounted for in previous studies. Finally, we shed more light on these associations in Sweden, which features marked intergenerational processes underlying fertility behaviour (e.g., Stanfors and Scott 2013), despite the strong welfare institutions minimising social disadvantage and weakening the dependence from parental resources already at young ages.

The empirical analyses are based on combined sequences of yearly marital and childbearing states between ages 15 and 30 from two generations, utilising data from Swedish population registers and dyadic sequence analysis. We draw a representative sample $(\mathrm{N}=2990)$ of men and women born between 1975 and 1980, who all became parents before age 20. To address the intergenerational reproduction of family trajectories, we compare their family sequences to those of their fathers and mothers, as well as to those of parents of birth cohort peers. Furthermore, we use regression analysis to assess whether previously identified predictors of intergenerational status inheritance are also relevant when addressing the intergenerational reproduction of family life courses.

\section{Background}

The investigation into whether, and how, family-forming behaviour is repeated within families has gained increased attention in recent years. There have been a number of studies into the strength of the intergenerational correlation (between parents and their children) and family background correlations (between siblings) of age at first birth, finding an overwhelming positive relationship (e.g., Barber 2001; Murphy 2013; Murphy and Knudsen 2002; Stanfors and Scott 2013; van Bavel and Kok 2009). These studies show that close kin are more likely to have similar family 
formation timing compared to not-so-close kin or non-kin. Furthermore, research in western contexts has found that these intergenerational associations have become stronger over time. Only recently, in a context of increasingly changing and diversified family patterns, have the levels of intergenerational persistence stabilised (Kolk et al. 2014; Murphy and Wang 2001; Steenhof and Liefbroer 2008).

That children to teenage parents are more likely to become teenage parents themselves, even when controlling for other background factors, has been found true for teenage mothers (e.g., Meade et al. 2008; Wahn and Nissen 2008; Wall-Wieler et al. 2016) as well as for teenage fathers (e.g., Sipsma et al. 2010). However, not much knowledge exists concerning the continued family formation of teenage parents. Some previous studies have identified low rates of marriage (Manning and Cohen 2015; Oberlander et al. 2010) but high rates of cohabitation (Manning and Cohen 2015) among teenage mothers, with rates of marriage and cohabitation differing over ethnicities (Eshbaugh 2008). Furthermore, teenage mothers have shown high total parity (Olausson 2001) and rapid repeat pregnancies among very young teenage mothers, and mothers with low levels of social support (Kalmuss and Namerow 1994; Manlove et al. 2000; Reese and Halpern 2017).

\section{Intergenerational correlations in family formation trajectories}

It is worth noting that the bulk of this empirical evidence is based on the analysis of cross-sectional outcomes, comparing age at first childbirth across two generations (Balbo et al. 2013). Yet, it can be argued that the study of family events along a larger set of family transitions in the individual life course, instead of their analysis in isolation, provides a better context for understanding family formation patterns and related outcomes. Trajectory-based approaches have previously been employed to understand family life courses better in connection to childlessness (Jalovaara and Fasang 2017), gender and education (Jalovaara and Fasang 2015) and health (Barban 2013; O'Flatherty et al. 2016).

Addressing questions of family-of-origin effects, some emerging research has extended trajectory-based analysis to the study of separate, but related, life courses such as those of parents and children. Liefbroer and Elzinga (2012) pioneered the utilisation of dyadic sequence analysis, comparing sequences of family life course states from age 15 to age 30, for 351 parent-child dyads from the American National Survey of Families and Households. They concluded that intergenerational transmission of family formation trajectories occurs despite pervasive changes in family trajectories across generations (Liefbroer and Elzinga 2012). Their evidence for intergenerational transmission of family life courses is based on comparisons between related dyads (consisting of two biologically-related individuals from two generations) and unrelated dyads (consisting of two biologically non-related individuals from two generations). They argued that the life courses of related dyads should be more similar than those of unrelated dyads for transmission processes to be in place. ${ }^{1}$

\footnotetext{
${ }^{1}$ Liefbroer and Elzinga (2012) proposed that "the similarity between trajectories of [related dyads consisting of] parents and children should, on average, be larger than similarities between trajectories of
} 
Using a similar research design, Raab et al. (2014) studied family background effects using Finnish register data. They compared dyads consisting of siblings (related dyads) with dyads consisting of two biologically non-related individuals of the same birth cohort (unrelated dyads). They found that family trajectories were moderately more similar among sibling dyads than among unrelated dyads, even when equalising siblings' and unrelated dyads' parental background by assigning non-related individuals based on background characteristics, concluding that shared parental background characteristics did little to account for family-forming behavioural patterns in Finland.

Yet another approach to the examination of family formation trajectories through sequence analysis was employed by Fasang and Raab (2014), who used multichannel sequence analysis to examine the concrete family formation patterns that are likely to be similar between parents and children, as well as those that are likely to be contrasting. They used information about American middle-class families, from the Longitudinal Study of Generations distinguishing between strong and moderate intergenerational transmission, as well as intergenerational contrast. Their results showed clear differences between types of intergenerational patterns, where children who reported close emotional bonds to their parents were more likely to follow similar family trajectories, whereas children who reported having poor relationships with their parents tended to follow a contrasting pattern of childlessness. Overall, the results from Liefbrorer and Elzinga (2012), Raab et al. (2014) and Fasang and Raab (2014) illustrate that not only specific behaviour such as age at first birth, but also complete patterns of family behaviour, seem to be transmitted from the parents to children.

\section{Mechanisms of intergenerational correlation of family formation behaviour}

Central for our study is the notion of linked lives, a key concept in the life course theory framework (Elder 1998). This principle implies that the life courses of parents and children are linked and influence each other through emotional, social, and economic support. In this regard, the intergenerational correlation in overall family behaviour can be explained through socialisation, where parents may transmit values and attitudes to children about what they perceive as desirable family behaviour (Bernardi and Klärner 2014). Alternatively, children may learn about family behaviours and their consequences from observing their parents. Teenage parenthood often has little societal acceptance, but levels of approval are higher in certain subpopulations with higher prevalence of early childbearing (Bernardi and Klärner

Footnote 1 (continued)

randomly chosen [unrelated] dyads consisting of a person of the parental generation and a person of the child's generation". 
2014), and particularly among parents who themselves have experienced early parenthood. Close family in these contexts might be more encouraging to these fertility decisions and lend emotional and functional support after childbirth. Hence, early family formation trajectories (and its replication from the previous generation) could become more viable for individuals coming from backgrounds with early family formation behaviour in previous generations, such as low socio-economic contexts. It is worth noting that socialisation of family behaviours and values has previously been argued to lead to stronger support for non-normative family trajectories, when taking place already in contexts of non-normative family structures, such as families who has gone through divorce and re-marriage (Cunningham and Thornton 2006); hence children from such backgrounds might be expected to follow more heterogeneous paths. Both similar and contrasting family-related behaviour across generations can be anticipated from mechanisms that emphasise socialisation and value transmission (e.g., Kahn and Andersson 1992; Fasang and Raab 2014; Sassler et al. 2009).

The transmission of economic, cultural and social status, and resources has also been proposed as an explanation for intergenerational correlations of family life courses, through an indirect causal path. Parents with higher socio-economic backgrounds often transmit higher education and career aspirations to their children (Baker et al. 2014; McCulloch 2017; Schoon and Parsons 2002). These correlations have prevailed despite the expansion of the educational system that led to educational mobility of recent generation (Schofer and Meyer 2005). Having access to economic capital also means better opportunities to support participation in higher education as an alternative to early childbearing. These opportunities could be used as economic leverage, since they can be withheld, investing these parents with sanctioning powers that they can use to exert social pressure in order to enforce their expectations (Bernardi 2003). Given this, we can expect individuals from high socio-economic backgrounds to be surrounded by both resources and values that promote continued education before further family formation, impacting the continued family trajectory they follow after becoming a teenage parent.

Recent research in Sweden has shown that family socio-economic background characteristics only accounted for a limited part of the intergenerational transmission of age at first birth (Stanfors and Scott 2013). In contrast, in an American context, Kahn and Andersson (1992) found that certain socio-economic family characteristics accounted for a large portion of the intergenerational transmission of teen parenthood, especially among white women. This raises the question of whether the welfare context of Sweden buffers some of the economic effects, leaving us with mechanisms more related to social value transmission to explain the connections between family background and family formation, rather than economic resources.

\section{The Swedish context}

Despite certain consistency in family patterns across advanced economies, international comparative research has shown differences in the strength of the intergenerational continuity in family formation behaviour such as age at first child (Murphy 2013) or divorce (Dronkers and Haerkoenen 2008). Hence, it is important to 
understand the nature and strength of mechanisms of intergenerational persistence of childbearing behaviour outside the Anglo-Saxon countries where most research has been focused.

In our study, we focus on a national context with a relatively low incidence of teenage parenthood. Age at first birth is particularly high in Sweden in comparison to the United States, but also to the OECD average (OECD 2016b). Furthermore, a postponement trend has been observed, where the mean age at first child for women rose from 24.4 in 1975 and 25.3 in 1980 (Gustafsson 2003) to 29.2 in 2016 (Statistics Sweden 2017). ${ }^{2}$ Teenage parenthood was not even prominent in Sweden in the second half of the twentieth century, and levels have been dropping steeply between the end of the 1960s and the beginning of the 1980s; and remained low thereafter (World Bank 2017). Teenage parenthood rates in Sweden are lower than in other western countries (Darroch et al. 2001), with about 5.6 births occurring per 1,000 women aged 15-19 in 2014 (World Bank 2017). This low prevalence can be attributed to the wide availability of state-subsidised contraceptives (Socialstyrelsen 2016) combined with sexual education in the educational curriculum since 1956 (Edgardh 2002), leading to Swedish youth having both the knowledge of, and access to contraception, as well as availability of abortions without parental consent. This can explain why Sweden has a lower prevalence of teenage pregnancy than countries such as the UK, US, and Canada (Darroch et al. 2001), and why $80 \%$ of teenage pregnancies in Sweden are ended through abortion (Statens folkhälsoinstitut 2011). The emphasis on education, contraception and available abortion makes the group of teenagers who pass through all these stages of dissuasion, a highly selected group of parents.

We note that the dissuasive effect of the above-mentioned policies could be counterbalanced by welfare institutions offering wide support to those who decide to embark on parenthood at very young ages. With the worldwide expansion of the higher education system (Schofer and Meyer 2005), the number of registered university students doubled in Sweden between the beginning of 1990s and 2017 (Statistics Sweden 2017). This expansion of higher education has been especially evident for women, who now have both higher grades and higher levels of education than men (Statistics Sweden 2017). This means that women today, in Sweden as elsewhere, have to consider the possible losses in terms of career and income, as well as possibilities for work/family balance when thinking about having children (Daly 2005). What makes Sweden, together with other Scandinavian contexts, special within the global phenomenon of educational expansion, is the availability of welfare support. Among others, teenage parents have access to parental leave, additional social support, and they can enrol in adult educational programs if they have dropped out of school. Thus, it might be relatively easier for individuals with limited resources to follow the footsteps of their parents. However, institutional support opens up alternatives to follow an independent life to teenage parents, thus possibly weakening the influence of the families of origin. Even so, teenage parenthood in

\footnotetext{
${ }^{2}$ For men, the mean age at first child in 2015 was 31.5 (Statistics Sweden 2017).
} 
Sweden, for both men and women, is still associated with socio-economic disadvantage (Kaluczar 2018).

\section{Method and Data}

\section{Population and data}

Our study requires rich, longitudinal information covering the life courses of two generations. To this end, we have collected data from the Umeå SIMSAM lab. The dataset includes the entire population living in Sweden between 1960 and 2010, with individual information collected on a yearly basis, drawn from different Swedish administrative registers. The dataset enables individuals to be linked to their family members and covers relevant information for this study, such as complete marital and childbearing histories, and other relevant demographic information and socio-economic living conditions.

Our study population is divided into a younger generation and an older generation. The younger generation is our focal study population and contains all individuals, born in Sweden between 1975 and 1980, and who had a child before the age of 20. The six birth cohorts consist of 538,678 individuals. Individuals registered as living outside of Sweden between ages 15 and 30, or whose parents were registered as living outside of Sweden between ages 15 and 30, were omitted from the study because of unavailable and incomplete information, leaving the study population with 520,156 individuals. Out of these, 9652 individuals fulfil our inclusion criteria, and became parents before the age of 20. Since our register data is comprehensive, we can include both teenage mothers $(n=7573)$ and teenage fathers $(n=2079)$. Due to processing limitations, a random sample of teenage parents was taken, where teenage fathers were oversampled due to their low prevalence. The final sample consisted of 3000 teenage parents $(n=1500$ teenage mothers and $n=1500$ teenage fathers). The study population making up the older generation includes all parents of the focal study population $(n=5947)$. In addition, the older generation sample includes a random draw of individuals, unrelated to the younger generation sample, who had a child between 1975 and $1980(n=5990)$. For the empirical analysis, individuals of the younger generation were paired with their biological parents thus making up intergenerational dyads of family-related individuals or related dyads. In addition, individuals of the younger generation were paired with random nonfamily-related individuals from the older generation, creating unrelated dyads. After deleting dyads with missing information in key variables for analysis, our analytical sample consisted of 11,696 unique dyads. ${ }^{3}$

\footnotetext{
${ }^{3}$ Our original sample consisted of 12,000 unique dyads. We eliminated 304 dyads due to missing information on family level covariates (i.e. birth order, maternal education, maternal income and family structure at age 15). Overall, the amount of missing data was trivial, affecting only $2.5 \%$ of the original sample.
} 


\section{Analytical strategy}

To examine the intergenerational correlations in teenage family life course trajectories, we use methods for the analysis of state sequences. Sequences are ordered listings of fixed elements, such as family status over the life course. Introduced by Andrew Abbott in the early 1990s, sequence analysis found its way into the social sciences due to its ability to identify patterns in sequences, which are representations of trajectories (Abbott 1995). The most common approach to sequence analysis consists of the visualisation of sequences and the examination of similarity across sequences to establish patterns using sequence alignment algorithms such as Optimal Matching (Aisenbrey and Fasang 2010). We follow extensions to dyadic sequence analysis in Elzinga and Liefbroer (2007) or Raab et al. (2014) to examine correlations in family state sequences across generations. To determine whether any observed correlation is due to family-related processes of reproduction (and not chance or wider societal processes), we compare each teenage parent or focal individual's family state sequence within a related dyad and an unrelated dyad, regarding family ties to dyad members. The sequence analysis in this study was implemented with the help of the TraMineR package for R (Gabadinho et al. 2011).

We define family sequences for the younger generation and the older generation in the same way. Each sequence consists of 16 elements, representing yearly observations of family states between ages 15 and 30. Each sequence element can take one of the five categories of possible combinations of marital status and number of children. The five family state categories are "childless", "unmarried, 1 child", "married, 1 child", "unmarried, 2+ children", "married, 2+ children". Category choice reflects both theoretically-based states of family formation processes, as well as availability of detailed information in the dataset. Due to the structure of Swedish administrative registers, we cannot capture cohabitation with a partner if there is no common child. Furthermore, household states of unmarried cohabitation with children were not available for the parental generation. The solution of treating cohabitation in the younger generation as comparable with being married in the older generation is not viable since Sweden became a pioneer of cohabitation without marriage in the late 1960s (Bernhardt and Hoem 1985). Thus, categories including "unmarried" status refer to both single-never married, cohabiting, separated from cohabitation, and divorced. ${ }^{4}$ In addition, we do not consider the situation of married cohabitation without children because household states of marriage without children were uncommon for the focal individuals, partly because they became parents before typical marriage age. Instead, the pre-parenthood "no children" states are not sensitive to partnership status. For number of children, a cut-off at two or more children for the upper category reduces unnecessary complexity in the sequences, where 2 children or more before age 30 can be viewed as an indicator for being family oriented.

\footnotetext{
${ }^{4}$ Widowhood is a rare state in this stage of the life course, and individuals who lost their spouse were removed from the sample since it has different implications for early family formation.
} 
We compare family state sequences within dyads among pairs of individuals of two generations to address the degree of persistence in teenage family formation trajectories across generations. Among individuals of the younger generation, each sequence is compared four times-twice within related dyads, with the mother's and father's sequences, and twice within unrelated dyads, with the parents of birth cohort peers. To compare sequences, we calculate the dissimilarity across each pair of sequences, using a Dynamic Hamming Distance algorithm (Lesnard 2010). We define dissimilarity by setting transformation costs (i.e., how many changes in an element of a sequence, with an associated cost, are needed to transform one sequence into a reference sequence) that combine empirical transition rates across states for each age period with theory-based element substitution costs. The measure we obtain reflects the dissimilarity between the pair of sequences of each dyad, where a value of (or close to) zero indicates that the two sequences are (almost) identical. The higher the values relative to other sequences, the more unequal the family life courses across the dyad were. It is worth noting that the dissimilarity measure is a product of the transformation costs when comparing sequences, as well as the length and number of states of the sequence, and it is only meaningful for sample group comparisons. We tested the sensitivity of our dissimilarity measure using different theoretical transformation costs with an emphasis on duration and order of states instead of timing and did not observe significant variations in the results.

If we find a statistically significant lower average dissimilarity in family sequences across related dyads than across unrelated dyads, we will consider this evidence for intergenerational persistence in the family formation patterns from parents to children, that is intergenerational correlation operates through family-related processes. In contrast, if the difference in average dissimilarity is not significant or is unexpectedly significant in the opposite direction, then we will conclude that any intergenerational correlation is not related to family processes but societal processes affecting continuity on the life course of teenage parents in the wider society. We note that results will provide more nuanced evidence on family-forming behaviour in that it relates to similarity in long-term family formation patterns (until age 30), not necessarily being evidence for same age at family formation. This will allow us to extract conclusions about further relevant aspects of intergenerational processes of family life course among contemporary teenage parents, such as marriage and repeated childbearing over the early adulthood stage. We test differences in gender permutations of focal individuals and individuals of the parental generation to address possible gender differences.

In our last step, we apply multilevel regression models to assess antecedents of the intergenerational correlation in family life courses. Multilevel models are deployed, as these allow for the specification of individual specific intercepts that account for the non-independence of repeated individual observations (i.e., individuals of each generation can be part of more than one dyad). We use the dyadic similarity measure, normalised to a range between 0 and 100, as a dependent variable in a two-level model estimated using a maximum likelihood estimator. We test whether intergenerational correlations of family trajectories can be explained or moderated by characteristics of socio-economic and family background. To 
this end, we follow a stepwise approach with inclusion of relevant variables in an additive fashion.

Model 1 is a base model that includes the type of dyad (i.e., indicator for related dyad, reference unrelated dyad), the gender composition of the dyad (i.e., three indicators for male-male, female-female, female-male and male-female dyads), as well as the focal individual's year of birth (not shown in main table, full models shown in Appendix 1). In Model 2, we add family structure and socio-economic measures, measured when the focal individual (younger generation) was 15 years old. This includes sibling order (calculated by ranking all maternal siblings by birth year), number of siblings (calculated from number of children by mother), family structure (four categories: living with both parents being the reference category, stepfamily living with one parent and a step-parent with common children, single parent living with one parent and possibly a step-parent, or other ${ }^{5}$ ), mean income of mother (four quartile categories, with quartile 1 as the reference category), and educational level of mother (three categories, 9 years or less of compulsory school as the reference category, upper secondary education and higher education). ${ }^{6}$ In Model 3, we add interaction effects of type of dyad (unrelated or related) with all other family structure and socio-economic variables. The interaction enables us to assess the extent to which background characteristics do actually matter for intergeneration correlations in family trajectories overall and within-families, between parents and children.

\section{Results}

\section{Family sequences and within-dyad sequence comparisons}

Comparing the sequence patterns of the younger generation and their parents (older generation, related individuals), shown in Fig. 1, we find larger differences in family states over generations than over gender. With age along the $\mathrm{x}$-axis and proportion of individuals in each state (represented by colours) on the y-axis, Fig. 1 reveals that most teenage childbearing occurs during the late teenage ages, with only about 20 percent of men and women from the younger generation becoming parents before age 18. Additionally, most childbearing is in the context of non-marital unions or lone parenthood across both genders and generations. Figure 1 further reveals that the prevalence of a second child is similar across generations, and with both generations not marrying until the second child, if at all.

Figure 2 shows the averaged distances, here on described as 'discrepancies', resulting from the sequence comparisons for each type of dyad and 95 percent confidence intervals, where larger values represent contrasting family trajectories across

\footnotetext{
${ }^{5}$ For individuals in the Other category, we are not able to identify their living situation apart from them not belonging to any of the other three categories. An important subgroup are likely individuals living in foster care. Individuals in the Other category might have moved out of home, but it is worth noting that young individuals moving to attend school are likely still registered as living in the parental home.

${ }^{6}$ Sensitivity analysis through multilevel regression models including (older generation) mothers' age at first birth as a covariate was conducted. More information available upon request.
} 

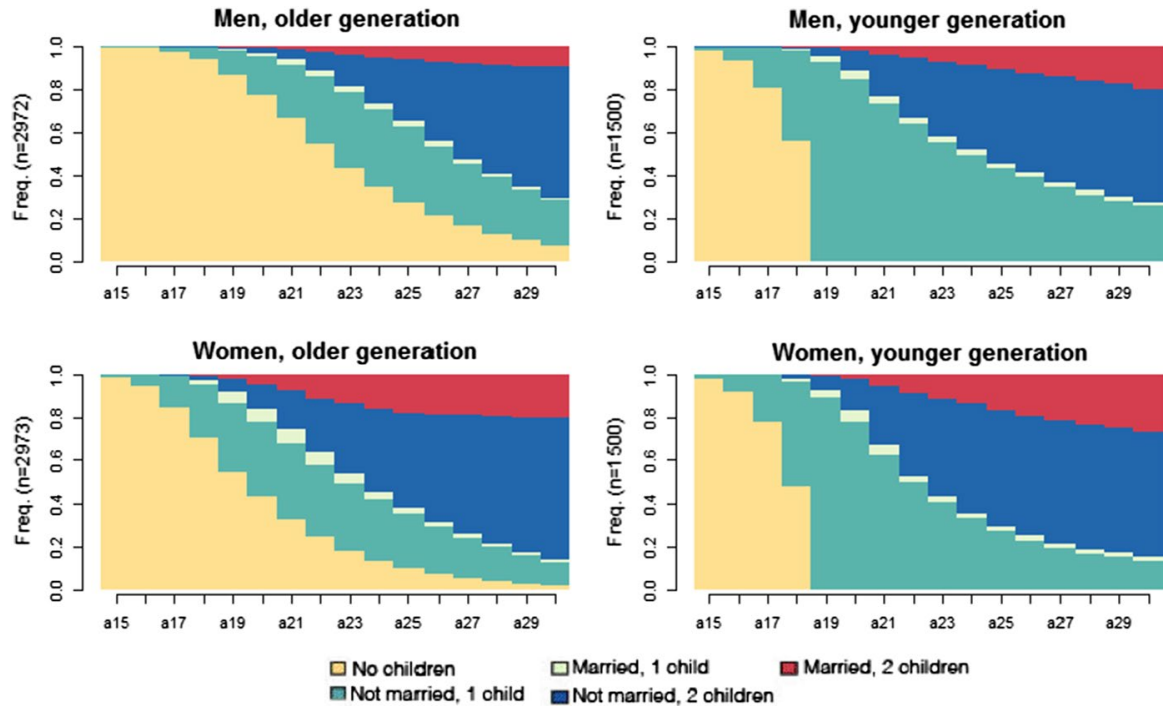

Fig. 1 State distribution plots of family sequences by individual's generation and gender. Note Data, Umeå SIMSAM lab

each pair of individual sequences, and lower values represent more similar family trajectories across each pair of individual sequences. In this analysis, initial evidence for intergenerational persistence of family trajectories within families would be based on observing smaller values (i.e., less discrepancy and more similarity across pair of sequences) among related dyads, consisting of family members, than among unrelated dyads.

We find mostly smaller values (i.e., less discrepancy between trajectories) for related dyads than for unrelated dyads for both teenage mothers and teenage fathers. These patterns are consistent among related and unrelated dyads holding constant the gender of the older generation. That is, we find that teenage mothers' family trajectories are more similar to those of their mothers (Woman, related) than those of women who are parents of birth cohort peers (Woman, unrelated) and that teenage fathers are more similar to those of their fathers (Man, related) than those of unrelated men in the older generation (Man, unrelated). The pattern of less discrepancy for related dyads than for unrelated dyads in Fig. 2 also extends to most comparisons across genders of the older generation. It follows that teenage mothers' family trajectories resemble their mothers' trajectories more than those of their fathers. For young men, we see the same tendency, however the confidence intervals overlap. Despite this, we take our overall findings as initial evidence for persistence of family trajectories after an early birth of the first child across generations within families. 


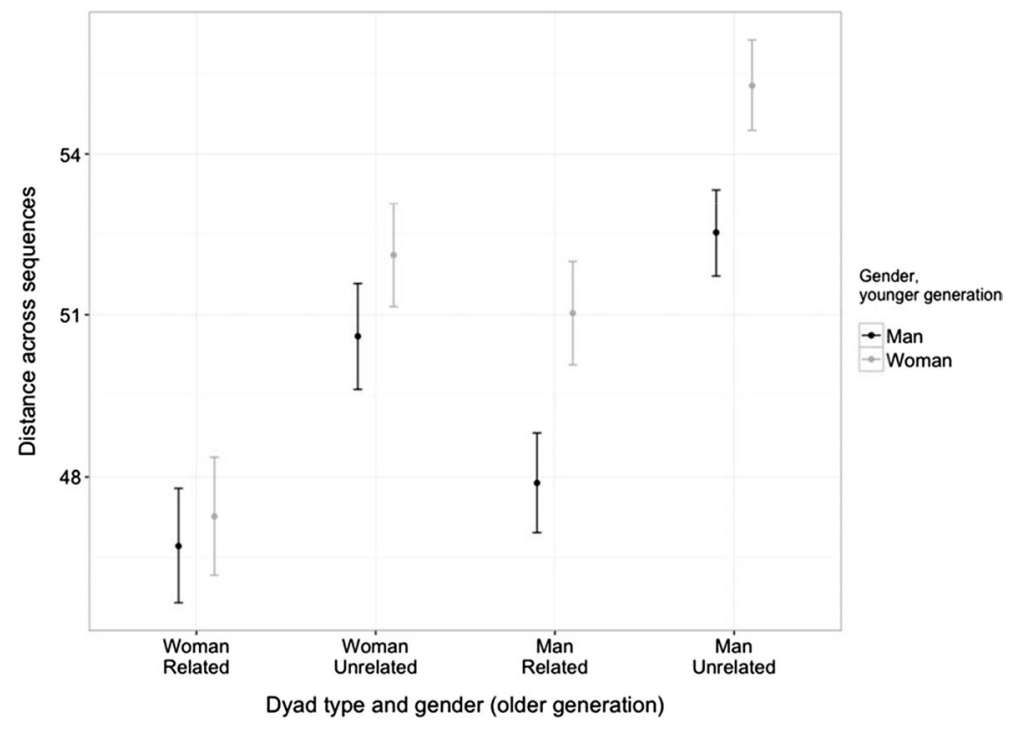

Fig. 2 Average discrepancy across generations in family sequences (by type of intergenerational dyad and gender). Note Dots are average distances (discrepancy) of sequences across dyads, and spikes are 95\% confidence intervals. Younger generation (man or woman) refers to individuals born between 1975 and 1980 who became teenage parent. Older generation (man or woman) refers to younger generation's parents (related) or randomly selected parents of individuals born between 1975-80 (unrelated). Data: Umeå SIMSAM lab

\section{Regression analysis}

Our second aim is to examine the factors associated with the observed intergenerational persistence in life course trajectories. To this end, we use multilevel regression analysis where our dependent variable is dyad discrepancy i.e., the calculated distance between the two individual sequences a dyad is made up of. Here, a negative coefficient means the two sequences have a lower discrepancy i.e., are more alike. A positive coefficient means that the individuals in the dyad have a larger discrepancy i.e., are less alike. The first model in Table 1 contains a dummy variable, related dyad, indicating whether the dyad is a related dyad (1) containing a focal individual and his or her parent, or an unrelated dyad (0) comprising a focal individual and an unrelated adult. Here, we focus on the gender composition of the dyad (i.e., three indicators for male-male, female-female, female-male and male-female dyads). In the second model, we include family background variables, and can thus study how these factors relate to intergenerational persistence of family formation trajectories between the older and younger generation. The last regression, Model 3, includes interaction effects between the type of dyad (related dyad versus unrelated dyad) so we can draw conclusions about whether dyad compositions and background factors explain similarities between the older and the younger generations as a whole (unrelated dyads) or rather demonstrate persistence within families (related dyads). The regression analysis contains all individual and parental 
Table 1 Predictors of discrepancies in family trajectories across generations (Linear Multilevel model)

\begin{tabular}{|c|c|c|c|c|c|c|}
\hline \multirow{2}{*}{ Dyadic level } & \multicolumn{2}{|c|}{ Model 1. coeff. (SE) } & \multicolumn{2}{|c|}{ Model 2 coeff. (SE) } & \multicolumn{2}{|c|}{ Model 3 coeff. (SE) } \\
\hline & & & & & & \\
\hline $\begin{array}{l}\text { Related dyad (reference unrelated } \\
\text { dyad) }\end{array}$ & $-4.419 * * *$ & $(0.302)$ & $-4.419^{* * *}$ & $(0.302)$ & -1.625 & $(1.758)$ \\
\hline \multicolumn{7}{|l|}{ Dyad gender composition (generation) } \\
\hline Man (younger): man (older) & Ref & & Ref & & Ref & \\
\hline Woman (younger): man (older) & $2.810 * * *$ & $(0.549)$ & $2.944 * * *$ & $(0.546)$ & $2.649 * * *$ & $(0.692)$ \\
\hline $\begin{array}{l}\text { Woman (younger): man (older) } \\
* \text { related dyad }\end{array}$ & & & & & 0.589 & $(0.851)$ \\
\hline Man (younger): woman (older) & $-1.513^{* * *}$ & $(0.425)$ & $-1.513^{* * *}$ & $(0.425)$ & $-1.915^{*}$ & $(0.599)$ \\
\hline $\begin{array}{l}\text { Man (younger): woman (older) } \\
* \text { related dyad }\end{array}$ & & & & & 0.805 & $(0.847)$ \\
\hline Woman (younger): woman (older) & -0.668 & $(0.549)$ & -0.534 & $(0.546)$ & -0.425 & $(0.692)$ \\
\hline $\begin{array}{l}\text { Woman (younger): woman } \\
\text { (older gen.) } * \text { related dyad }\end{array}$ & & & & & -0.218 & $(0.851)$ \\
\hline \multicolumn{7}{|l|}{ Individual level } \\
\hline Sibling order: first-born child & & & Ref & & Ref & \\
\hline Second-born child & & & $-2.223^{* * *}$ & $(0.555)$ & $-1.388^{*}$ & $(0.665)$ \\
\hline Second-born child $*$ related dyad & & & & & $-1.672^{*}$ & $(0.734)$ \\
\hline Third- or later-born child & & & $-2.502 * * *$ & $(0.657)$ & 0.115 & $(0.788)$ \\
\hline $\begin{array}{l}\text { Third- or later-born child } * \text { related } \\
\text { dyad }\end{array}$ & & & & & $-5.234^{* * * *}$ & $(0.870)$ \\
\hline Number of siblings: only child & & & Ref & & Ref & \\
\hline One sibling & & & -2.134 & $(1.141)$ & -1.764 & $(1.368)$ \\
\hline One sibling * related dyad & & & & & -0.741 & $(1.510)$ \\
\hline Two Siblings & & & -1.385 & $(1.147)$ & -0.625 & $(1.375)$ \\
\hline Two siblings $*$ related dyad & & & & & -1.519 & $(1.518)$ \\
\hline Three or more siblings & & & -1.792 & $(1.176)$ & -1.602 & $(1.410)$ \\
\hline Three or more siblings * related dyad & & & & & -0.380 & $(1.557)$ \\
\hline $\begin{array}{l}\text { Family structure (age 15): traditional } \\
\text { family }\end{array}$ & & & Ref & & Ref & \\
\hline Stepfamily & & & $-2.995 * * *$ & $(0.684)$ & $-1.746^{*}$ & $(0.821)$ \\
\hline Stepfamily $*$ related dyad & & & & & $-2.499^{* *}$ & $(0.906)$ \\
\hline Single parent & & & $-2.322^{* * *}$ & $(0.515)$ & -0.379 & $(0.618)$ \\
\hline Single parent $*$ related dyad & & & & & $-3.886^{* * *}$ & $(0.682)$ \\
\hline Other & & & $-3.178^{*}$ & $(1.365)$ & -1.715 & $(1.636)$ \\
\hline Other $*$ related dyad & & & & & -2.926 & $(1.806)$ \\
\hline Mean income (of mother): quartile 1 & & & Ref & & Ref & \\
\hline Quartile 2 & & & 1.230 & $(0.658)$ & 0.376 & $(0.789)$ \\
\hline Quartile $2 *$ related & & & & & 1.707 & $(0.871)$ \\
\hline Quartile 3 & & & 0.527 & $(0.680)$ & -0.067 & $(0.815)$ \\
\hline Quartile $3 *$ related & & & & & 1.188 & $(0.900)$ \\
\hline Quartile 4 & & & 0.723 & $(0.718)$ & -0.506 & $(0.861)$ \\
\hline Quartile $4 *$ related & & & & & $2.457^{* * *}$ & $(0.950)$ \\
\hline $\begin{array}{l}\text { Educational level (of mother): primary } \\
\text { or less }\end{array}$ & & & & & Ref & \\
\hline
\end{tabular}


Table 1 (continued)

\begin{tabular}{|c|c|c|c|c|c|c|}
\hline \multirow[b]{2}{*}{ Secondary school } & \multicolumn{2}{|c|}{ Model 1. coeff. (SE) } & \multicolumn{2}{|c|}{ Model 2 coeff. (SE) } & \multicolumn{2}{|c|}{ Model 3 coeff. (SE) } \\
\hline & & & -0.604 & $(0.789)$ & -0.798 & $(0.622)$ \\
\hline Secondary school $*$ related & & & & & -0.389 & $(0.687)$ \\
\hline Higher education & & & $1.604^{*}$ & $(0.789)$ & 0.354 & $(0.946)$ \\
\hline Higher education $*$ related & & & & & $2.499^{*}$ & (1.044) \\
\hline Constant & $50.727 * * *$ & $(0.626)$ & $54.539 * * *$ & $(1.315)$ & $53.142 * * *$ & $(1.575)$ \\
\hline Observations & 11,696 & & 11,696 & & 11.696 & \\
\hline AIC & $100,949.2$ & & $100,892.0$ & & $100,802.9$ & \\
\hline
\end{tabular}

Linear Multilevel regression models on dyad discrepancies. All model specifications include birth year Full models are shown in Table 1 in Appendix 1. The dependent variable is the normalised Dynamic Hamming distance between sequences of family states within dyads composed of individuals of two generations. Related dyads consist of individuals drawn within the same family (i.e., parent and offspring). Unrelated dyads consist of individuals drawn across families. Data: Umeå SIMSAM lab

$* p<0.05 ; * * p<0.01 ; * * * p<0.001$

correlates on level 1 , with person specific $(n=3000)$ intercepts. The discrepancy measure is normalised to a range of 0 to 100 , with a standard deviation of 23 .

Starting with the first model in Table 1 , we can see that the family patterns of the younger generation have significantly lower discrepancy to their parents than to the unrelated adults, indicated by the negative coefficient of -4.419 for the related dyad variable. From the varying effects between the different gender composition dyads, we can conclude that it is indeed relevant to take gender composition into consideration. First, looking at the last dyads in Model 1, woman (younger): woman (older), we see no significant effect in relation to the reference category man (younger) / man (older).

The significant effects found in Model 1 are, instead, between our cross-gender dyads. For the dyad consisting of woman (younger) / man (older), we see a larger discrepancy between generations, with a significant positive coefficient of 2.810 . This might not be surprising, as our teenage mothers by definition have become first time mothers at an early age, and men in general become parents later in life, which is also true for the older generation of men included here. Looking at the second cross-gender dyad, the dyad comprising of man (younger) / woman (older), we see a significantly smaller discrepancy, a coefficient of -1.513 , between generations i.e., the individuals in these dyads are more similar to each other than the man (younger) I man (older) are. This might seem counterintuitive but is likely a result of the selection of men who become teenage fathers. Investigating the sequences (Fig. 1), we can see that a large proportion of men go on to have a second child soon after the first, which is another factor that might explain why teenage fathers' trajectories are closer to those of women of the older generation. The general pattern is that women have children and marry at a younger age compared to men, thus contributing to the lower discrepancies between the two generations.

In Model 2, we add family level variables for our teenage parents, measuring sibling order, number of siblings, family structure at age 15, mean income of mother and educational level of mother. We see no change in the discrepancies of the younger and older generation, and the coefficient for the related dyad variable 
stays the same, -4.419 . The family variables in themselves, however, do affect the discrepancy between family formation trajectories between generations. For sibling order, being second or third/later born is associated with a smaller discrepancy between generations. While family size, measured by number of siblings, does not significantly affect the discrepancies between generations, the family structure at age 15 does. Compared to those who lived with both their biological parents (traditional nuclear family), individuals living in all other family types had a significantly lower discrepancies between generations, thus displaying higher similarity between the generations. Socio-economic factors had less impact on the intergenerational persistence between the two generations, with no difference in discrepancy over the distribution of mean income of mother. Educational level of mother had an effect, in that being the child of a highly educated woman did increase the discrepancies between generations.

In the last model, Model 3, we add interaction effects to the related dyad. This should help determine whether the persistence found in Model 2 is taking place within families (related dyads) or between generations as a whole (unrelated dyads). Controlling for these interaction effects, we see that the main effect of the related dyad variable turns non-significant, showing that the within-family persistence seen in Models 1 and 2 are channelled through family structure and socio-economic variables.

When looking at the gender composition dyads, we see that the same significant effects found in Model 2 remain. Controlling for interaction between the dyads and being related is, however, not significant. We can thus conclude that the effect of cross-gender dyads is not dependent on family ties, but instead illustrates persistence over generations as a whole.

With respect to sibling order, Model 3 reveals that being the second-born child not only makes the teenage parents have a somewhat lower discrepancy to the older generation as a whole $(-1.388)$, additionally it makes the teenage parents even more similar to their own parents $(-1.672)$. Being third-born or later, however, does not make the teenage parents more similar to the generation as a whole but instead seems to play an important role in decreasing the within-family discrepancies, with a discrepancy coefficient of -5.234 . The number of siblings in the family remains irrelevant to the in-between generation as well as within-family similarities.

Family structure at age 15 continues to be of importance for both in-between generation, and within-family, similarity. The general effect on the discrepancy between generations decreases for teenage parents who, at age 15, lived in a stepfamily, from -2.995 in Model 2 to -1.746 when controlling for interaction effects in Model 3. This decrease is paired with a significant interaction effect of living in stepfamilies and being related (-2.499), which suggests that individuals living in stepfamilies have larger discrepancies with their parents, as compared to individuals living with both of their parents. For individuals living in single parent households, however, the general effect between generations disappears while the decreased discrepancy is significant only within families (-3.886).

For mean income of mother, adding the related dyad interactions reveals that individuals from the highest income quartile have higher discrepancies to their parents (2.457), than individuals from the lowest income quartile. Similarly, with 
educational level of mother, we see that teenage parents with mothers having the highest educational level (2.499) are more discrepant to their parents, as compared to individuals with lower levels of maternal education.

\section{Discussion}

This research has addressed intergenerational correlations in family formation patterns among teenage parents. That is, the extent to which a similar set of family behaviours over the life course are experienced at about the same age by members of two generations, including teenage parents and their progenitors. To this end, we constructed sequences consisting of combined fertility and marital episodes from Swedish population register data. Using Optimal Matching, we examined the similarity in the structure of family sequences across individuals of a younger generation, consisting of teenage parents born between 1975 and 1980, and individuals of an older generation, comprising their parents. By adopting a sequence approach, our research considers family formation as a process that integrates the relevant family behaviours that follow and are contingent on the focus event: a teenage childbirth. This approach enables a more nuanced measurement of family-forming behaviour. In addition, we deploy dyadic sequence analysis to render evidence on intergenerational processes, departing from earlier research that examines exact matches in the age at childbearing between parents and children. Our approach considers that intergenerational correlations could be observed in similar-not necessarily the same- family patterns between parents and children. This acknowledges the dynamics of change in family life courses of recent decades, where it is increasingly difficult to find parents and offspring following the exact same patterns.

We find that the family trajectories of teenage parents are generally more similar to the family trajectories of their progenitors than to the family trajectories of unrelated individuals of the progenitor generation. This illustrates that previous knowledge on the reproduction of teenage childbearing within families can be extended to the long-term trajectories of teenage parents. Our research builds on two previous studies that found statistically significant correlations of standard or on-time family trajectories between parents and offspring (Liefbroer and Elzinga 2012) and across siblings (Raab et al. 2014). Our research extends these studies by showing that within-family correlations in family trajectories holds true even for non-normative and off-time and off-sequence family trajectories, such as those of teenage parents.

We addressed background antecedents of the intergenerational correlations in family trajectories in multivariate models that showed that teenage parents' childhood family structure and socio-economic status explain a large part of the similarity of their family trajectories with those of their progenitors. Among others, our models showed that the trajectories of teenage parents (in our sample of individuals from the younger generation) with highly educated mothers or from families of origin with higher incomes, were significantly less similar to the trajectories of their own parents than to a random individual (from the older generation). These findings contrast with those of Raab (2014) who, examining within-family similarities in trajectories across sibling dyads, found that trajectories of sisters with highly educated 
parents were more alike than those of sisters with less educated parents. We note that our subpopulation of teenage parents is following an out-of-norm, out-of-sequence type of trajectory that is already different from expectations. Given this, our results of lower intergenerational correlations among individuals from high socio-economic backgrounds is unsurprising. This is also confirmed by research on intergenerational correlations in age at childbearing, which finds that the reproduction of early childbearing related to economic disadvantage in childhood (e.g., Fletcher and Wolfe 2009; Lee 2010; Webbink et al. 2011). Our results also indicate that childhood family structure, particularly sibling order and family structure type at age 15, had a greater influence on the intergenerational correlations. Within-family similarities in family trajectories were greater among teenage parents who were in stepfamilies or single parent homes during childhood. The finding aligns with evidence on childhood experience in such alternative family structures that support non-normative family trajectories (Cunningham and Thornton 2006). Given that children are more often found in alternative family structures, one possible conclusion of this line of research is increasing heterogeneity in family life courses and intergenerational reproduction confined to normative family trajectories. Alternatively, a long trend of increased non-marital cohabitation (Bernhardt and Hoem 1985) and marital union instability in Sweden (Eurostat 2015) would challenge the conceptions of normative and alternative family patterns, perhaps being a reason why intergenerational correlations of family trajectories extends to the so-called off-time trajectories.

The relative importance of childhood family structure in comparison to socioeconomic factors in our results indicates that it is socialisation of values rather than economic opportunities that matter for the reproduction of family trajectories. This aligns with a prior study, showing that socio-economic background did little to account for intergenerational correlations in age at first birth in Sweden (Kolk 2014). The importance of value socialisation within families might explain why the intergenerational correlations remain even after shifts in educational attainment across generations due to educational expansion, and in the Swedish context of strong institutional support to young families. Swedish teenage parents incur no tuition for higher education, they can obtain specific support for parents within the student loan systems (CSN 2018) and have wide availability of affordable childcare, enabling family trajectories to run parallel to educational trajectories even for young parents from disadvantaged backgrounds. However, this does not seem to compensate for the importance of the type of family trajectories and family forms in which the individual grew up, neither for teenage mothers nor teenage fathers. Furthermore, as teenage parenthood becomes both less prevalent (World Bank 2017) as well as further removed from the average age at first child (Statistics Sweden 2017), accepting attitudes for these life choices within the own family might have increasing importance.

A limitation with the available data from the population registers is that it is only possible to identifying non-marital cohabitation where the partners have shared children, which limits our ability to map relevant behaviours in contemporary partnership such as re-partnering, non-married cohabiting couples. Additionally, population registers do not contain subjective measures such as attitudes and motivations. Such measures could be of importance for intergenerational transmission processes, 
mediating and explaining some of the family level correlates of intergenerational persistence. Along these lines, previous studies of intergenerational transmission and contrast of family formation trajectories showed that emotional closeness led to stronger intergenerational transmission (Fasang and Raab 2014). One should also keep in mind that the internationally low prevalence of teenage parenthood in Sweden, paired with a strong welfare context, could have implications for the direct transferability of results to other high prevalence contexts. Furthermore, it is important to note that this study, with its descriptive design, cannot make claims of causality. We can only identify intergenerational correlations.

Despite the limitations, it is worth noting the value of our perspective and results, which are best understood in the context of emerging research on the heterogeneity of family and educational trajectories of teenage parents (Kalucza, BaranowskaRataj \& Nilsson 2020; Diaz and Fiel 2016). This body of research has shown that the life changing event of parenthood at very early ages does not equate to a one and only life pattern, and that there is much heterogeneity in what takes place next that deserves further attention. Our study contributes to this literature, thus, by extending existing evidence on intergenerational processes in family formation patterns, made possible by the availability of high-quality Swedish population register data. In addition, ours is one of the few studies that looked into in early family formation of women as well as men, and the first to look into the associated intergenerational processes. As mentioned before, our research also innovates in using state-of-theart methods for the analysis of trajectories, such as dyadic sequence analysis, which enable us to improve and nuance comparison of family-forming behaviour across generations. We note that understanding how the diversity in family life courses after teenage parenthood evolves is an important next step to find ways to break the cycle of disadvantage associated to teenage parenthood in a number of contexts. We call for more research along these lines.

\section{Appendix 1}

\section{A1. Full model specifications (with birth year)}

\begin{tabular}{|c|c|c|c|c|c|c|}
\hline & $\begin{array}{l}\text { Model } 1 \\
\text { Coeff. (SE) }\end{array}$ & & $\begin{array}{l}\text { Model } 2 \\
\text { Coeff. (SE) }\end{array}$ & & $\begin{array}{l}\text { Model } 3 \\
\text { Coeff. (SE) }\end{array}$ & \\
\hline \multicolumn{7}{|l|}{ Dyadic level } \\
\hline $\begin{array}{l}\text { Related dyad (reference unrelated } \\
\text { dyad) }\end{array}$ & $-4.419 * * *$ & $(0.302)$ & $-4.419 * * *$ & $(0.302)$ & -1.625 & $(1.758)$ \\
\hline \multicolumn{7}{|c|}{ Dyad gender composition (generation) } \\
\hline $\begin{array}{l}\text { Man (younger): man (older) } \\
\text { Woman (younger): man (older) }\end{array}$ & $\begin{array}{l}\text { Ref. } \\
2.810 * * *\end{array}$ & $(0.549)$ & $\begin{array}{l}\text { Ref. } \\
2.944 * * *\end{array}$ & $(0.546)$ & $\begin{array}{l}\text { Ref. } \\
2.649 * * *\end{array}$ & $(0.692)$ \\
\hline
\end{tabular}




\begin{tabular}{|c|c|c|c|c|c|c|}
\hline & \multicolumn{2}{|l|}{$\begin{array}{l}\text { Model } 1 \\
\text { Coeff. (SE) }\end{array}$} & \multicolumn{2}{|l|}{$\begin{array}{l}\text { Model } 2 \\
\text { Coeff. (SE) }\end{array}$} & \multicolumn{2}{|l|}{$\begin{array}{l}\text { Model } 3 \\
\text { Coeff. (SE) }\end{array}$} \\
\hline $\begin{array}{l}\text { Woman (younger): man (older) } * \\
\text { related dyad }\end{array}$ & & & & & 0.589 & $\overline{(0.851)}$ \\
\hline Man (younger): woman (older) & $-1.513^{* * *}$ & $(0.425)$ & $-1.513 * * *$ & $(0.425)$ & $-1.915^{*}$ & $(0.599)$ \\
\hline $\begin{array}{l}\text { Man (younger): woman (older) * } \\
\text { related dyad }\end{array}$ & & & & & 0.805 & $(0.847)$ \\
\hline Woman (younger): woman (Older) & -0.668 & $(0.549)$ & -0.534 & $(0.546)$ & -0.425 & $(0.692)$ \\
\hline $\begin{array}{l}\text { Woman (younger): woman (Older } \\
\text { gen.) * related dyad }\end{array}$ & & & & & -0.218 & $(0.851)$ \\
\hline \multicolumn{7}{|l|}{ Individual level } \\
\hline Birth year: 1975 & Ref. & & Ref. & & Ref. & \\
\hline 1976 & 0.950 & $(0.744)$ & 1.046 & $(0.740)$ & 1.059 & $(0.887)$ \\
\hline $1976 *$ related dyad & & & & & -0.026 & $(0.979)$ \\
\hline 1977 & $1.686^{*}$ & $(0.761)$ & $1.785^{*}$ & $(0.763)$ & $1.952^{*}$ & $(0.968)$ \\
\hline \multicolumn{7}{|l|}{$1977 *$ related dyad } \\
\hline 1978 & 1.353 & $(0.804)$ & 1.406 & $(0.807)$ & 1.568 & $(0.968)$ \\
\hline \multicolumn{7}{|l|}{$1978 *$ related dyad } \\
\hline 1979 & $2.954 * * *$ & $(0.784)$ & $3.034 * * *$ & $(0.804)$ & $3.489 * * *$ & $(0.964)$ \\
\hline \multicolumn{7}{|l|}{$1979 *$ related dyad } \\
\hline 1980 & $3.617 * * *$ & $(0.773)$ & $3.776^{* * *}$ & $(0.790)$ & $4.166^{* * *}$ & $(0.947)$ \\
\hline \multicolumn{7}{|l|}{$1980 *$ related dyad } \\
\hline Sibling order: first-born child & & & Ref. & & Ref. & \\
\hline Second-born child & & & $-2.223^{* * *}$ & $(0.555)$ & $-1.388^{*}$ & $(0.665)$ \\
\hline Second-born child $*$ related dyad & & & & & $-1.672^{*}$ & $(0.734)$ \\
\hline Third- or later-born child & & & $-2.502 * * *$ & $(0.657)$ & 0.115 & $(0.788)$ \\
\hline $\begin{array}{l}\text { Third- or later-born child * related } \\
\text { dyad }\end{array}$ & & & & & $-5.234 * * *$ & $(0.870)$ \\
\hline Number of siblings: only child & & & Ref. & & Ref. & \\
\hline One sibling & & & -2.134 & $(1.141)$ & -1.764 & $(1.368)$ \\
\hline One sibling $*$ related dyad & & & & & -0.741 & $(1.510)$ \\
\hline Two Siblings & & & -1.385 & $(1.147)$ & -0.625 & $(1.375)$ \\
\hline Two siblings * related dyad & & & & & -1.519 & (1.518) \\
\hline Three or more siblings & & & -1.792 & $(1.176)$ & -1.602 & $(1.410)$ \\
\hline $\begin{array}{l}\text { Three or more siblings * related } \\
\text { dyad }\end{array}$ & & & & & -0.380 & $(1.557)$ \\
\hline $\begin{array}{l}\text { Family form (age 15): Traditional } \\
\text { family }\end{array}$ & & & Ref. & & Ref. & \\
\hline Stepfamily & & & $-2.995^{* * *}$ & $(0.684)$ & $-1.746^{*}$ & $(0.821)$ \\
\hline Stepfamily $*$ related dyad & & & & & $-2.499^{* *}$ & $(0.906)$ \\
\hline Single parent & & & $-2.322 * * *$ & $(0.515)$ & -0.379 & $(0.618)$ \\
\hline Single parent $*$ related dyad & & & & & $-3.886^{* * *}$ & $(0.682)$ \\
\hline Other & & & $-3.178^{*}$ & $(1.365)$ & -1.715 & (1.636) \\
\hline Other $*$ related dyad & & & & & -2.926 & $(1.806)$ \\
\hline Mean income (of mother): Quartile 1 & & & Ref. & & Ref. & \\
\hline Quartile 2 & & & 1.230 & $(0.658)$ & 0.376 & $(0.789)$ \\
\hline
\end{tabular}




\begin{tabular}{|c|c|c|c|c|c|c|}
\hline & $\begin{array}{l}\text { Model } 1 \\
\text { Coeff. (SE) }\end{array}$ & & $\begin{array}{l}\text { Model } 2 \\
\text { Coeff. (SE) }\end{array}$ & & $\begin{array}{l}\text { Model } 3 \\
\text { Coeff. (SE) }\end{array}$ & \\
\hline Quartile $2 *$ related & & & & & 1.707 & $(0.871)$ \\
\hline Quartile 3 & & & 0.527 & $(0.680)$ & -0.067 & $(0.815)$ \\
\hline Quartile $3 *$ related & & & & & 1.188 & $(0.900)$ \\
\hline Quartile 4 & & & 0.723 & $(0.718)$ & -0.506 & $(0.861)$ \\
\hline Quartile $4 *$ related & & & & & $2.457^{* *}$ & $(0.950)$ \\
\hline $\begin{array}{l}\text { Educational level (of mother): Pri- } \\
\text { mary or less }\end{array}$ & & & & & Ref. & \\
\hline Secondary school & & & -0.604 & $(0.789)$ & -0.798 & $(0.622)$ \\
\hline Secondary School $*$ related & & & & & -0.389 & $(0.687)$ \\
\hline Higher education & & & $1.604^{*}$ & $(0.789)$ & 0.354 & $(0.946)$ \\
\hline Higher education $*$ related & & & & & $2.499^{*}$ & $(1.044)$ \\
\hline Constant & $50.727 * * *$ & $(0.626)$ & $54.539 * * *$ & $(1.315)$ & $53.142 * * *$ & $(1.575)$ \\
\hline Observations & 11,696 & & 11,696 & & 11.696 & \\
\hline AIC & $100,949.2$ & & $100,892.0$ & & $100,802.9$ & \\
\hline
\end{tabular}

Linear Multilevel regression models on dyad distances. All model specifications include birth year $* p<0.05 ; * * p<0.01 ; * * * p<0.001$

Funding Open access funding provided by Umea University. The Umeå SIMSAM Lab data infrastructure used in this study was developed with support from the Swedish Research Council and by strategic funds from Umeå University.

\section{Declarations}

Conflict of interest The authors declare that they have no conflict of interest.

Open Access This article is licensed under a Creative Commons Attribution 4.0 International License, which permits use, sharing, adaptation, distribution and reproduction in any medium or format, as long as you give appropriate credit to the original author(s) and the source, provide a link to the Creative Commons licence, and indicate if changes were made. The images or other third party material in this article are included in the article's Creative Commons licence, unless indicated otherwise in a credit line to the material. If material is not included in the article's Creative Commons licence and your intended use is not permitted by statutory regulation or exceeds the permitted use, you will need to obtain permission directly from the copyright holder. To view a copy of this licence, visit http://creativecommons.org/licen ses/by/4.0/.

\section{References}

Abbott, A. (1995). Sequence analysis: New methods for old ideas. Annual Review of Sociology, 21(1), 93.

Aisenbrey, S., \& Fasang, A. E. (2010). New life for old ideas: The "Second Wave' of sequence analysis bringing the "Course" back into the life course. Sociological Methods and Research, 38(3), 420-462.

Assini-Meytin, L. C., \& Green, K. M. (2015). Long-term consequences of adolescent parenthood among African-American urban youth: A propensity score matching approach. Journal of Adolescent Health, 56(5), 529-535. 
Baker, W., Sammons, P., Siraj-Blatchford, I., Sylva, K., Melhuish, E. C., \& Taggart, B. (2014). Aspirations, education and inequality in England: insights from the effective provision of pre-school, primary and secondary education project. Oxford Review of Education, 40(5), 525-542.

Balbo, N., Billari, F. C., \& Mills, M. (2013). Fertility in advanced societies: A review of research. European Journal of Population-Revue Europeenne De Demographie, 29(1), 1-38.

Barber, J. S. (2001). Ideational influences on the transition to parenthood: Attitudes toward childbearing and competing alternatives. Social Psychology Quarterly, 64(2), 101-127.

Barban, N. (2013). Family trajectories and health: A life course perspective. European Journal of Population-Revue Europeenne De Demographie, 29(4), 357-385.

Bernardi, L. (2003). Channels of social influence on reproduction. Population Research and Policy Review, 22(5-6), 427-555.

Bernardi, L., \& Klärner, A. (2014). Social networks and fertility. Demographic Research, 30, 641-670.

Bernhardt, E., \& Hoem, B. (1985). Cohabitation and social background: Trends observed for Swedish women born between 1936 and 1960. European Journal of Population/revue Européenne De Démographie, 1(4), 375-395.

Billari, F., Goisis, A., Liefbroer, A. C., Settersten, R. A., Aassve, A., Hagestad, G., \& Speder, Z. (2011). Social age deadlines for the childbearing of women and men. Human Reproduction, 26(3), 616-622.

Buchmann, M. C., \& Kriesi, I. (2011). Transition to adulthood in Europe. Annual Review of Sociology, $37(1), 481-503$.

Cunnington, A. J. (2001). What's so bad about teenage pregnancy? Journal of Family Planning and Reproductive Health Care, 27(1), 36-41.

Cunningham, M., \& Thornton, A. (2006). The influence of parents' marital quality on adult children's attitudes toward marriage and its alternatives: Main and moderating effects. Demography, 43(4), 659-672.

CSN [The Swedish Board of Student Finance] (2018) English-Home equipment loan. Retrieved August 17, 2018. From https://www.csn.se/languages/english.html\#expand:svid10_7ceb52b315ad72aa59ee $3 \mathrm{~b} 11$

Daly, M. (2005). Changing family life in Europe: Significance for state and society. European Societies, 7(3), 379-398. https://doi.org/10.1080/14616690500194001.

Dannefer, D., Kelley-Moore, J., \& Huang, W. (2016). Opening the social: Sociological imagination in life course studies. In Handbook of the life course (pp. 87-110). Springer, Cham.

Darroch, J. E., Singh, S., \& Frost, J. J. (2001). Differences in teenage pregnancy rates among five developed countries: The roles of sexual activity and contraceptive use. Family Planning Perspectives, 33(6), 244.

Diaz, C. J., \& Fiel, J. E. (2016). The effect(s) of teen pregnancy: Reconciling theory, methods, and findings. Demography, 53(1), 85-116.

Dronkers, J., \& Haerkoenen, J. (2008). The intergenerational transmission of divorce in cross-national perspective: Results from the Fertility and Family Surveys. Population Studies-a Journal of Demography, 62(3), 273-288.

Edgardh, K. (2002). Adolescent sexual health in Sweden. Sexually Transmitted Infections, 78(5), $352-356$.

Elder, G. H. (1998). The life course as developmental theory. Child Development, 69(1), 1.

Elzinga, C. H., \& Liefbroer, A. C. (2007). De-standardization of family-life trajectories of young adults: A cross-national comparison using sequence analysis. European Journal of Population-Revue Europeenne De Demographie, 23(3-4), 225-250.

Eurostat (2015) Fertility rates by age. Brussels: Eurostat

Eshbaugh, E. (2008). Teen mothers: marriage, cohabitation, and educational achievement. Journal of Family Social Work, 11(1), 3-16.

Fasang, A. E., \& Raab, M. (2014). Beyond transmission: Intergenerational patterns of family formation among middle-class American families. Demography, 51(5), 1703-1728.

Fletcher, J., \& Wolfe, B. (2009). Education and labor market consequences of teenage childbearing evidence using the timing of pregnancy outcomes and community fixed effects. Journal of Human Resources, 44(2), 303-325.

Furstenberg, F. F. (1991). As the pendulum swings: teenage childbearing and social concern. Family Relations, 40(2), 127-138.

Gabadinho, A., Ritschard, G., Müller, N. S., \& Studer, M. (2011). Analyzing and visualizing state sequences in R with TraMineR. Journal of Statistical Software, 40(4), 1-37. 
Geronimus, A., \& Korenman, S. (1993). The socioeconomic costs of teenage childbearing-evidence and interpretation. Demography, 30(2), 281-290.

Gustafsson, S. (2003). Optimal age at motherhood. Theoretical and empirical considerations on postponement of maternity in Europe. Family, Household and Work, pp. 345-367.

Jalovaara, M., \& Fasang, A. E. (2015). Are there gender differences in family trajectories by education in Finland? Demographic Research, 33, 1241-1256.

Jalovaara, M., \& Fasang, A. E. (2017). From never partnered to serial cohabitors: Union trajectories to childlessness. Demographic Research, 36, 1703-1720.

Kahn, J. R., \& Anderson, K. E. (1992). Intergenerational patterns of teenage fertility. Demography, 29(1), 39.

Kalmuss, D., \& Namerow, P. (1994). Subsequent childbearing among teenage mothers-the determinants of a closely spaced 2nd birth. Family Planning Perspectives, 26(4), 149.

Kalucza, S. (2018). Mental health problems and social disadvantages as predictors of teenage parenthood: A register-based population study of Swedish boys and girls. Longitudinal and Life Course Studies, 9(2), 212-225. https://doi.org/10.14301/llcs.v9i2.444.

Kalucza, S., Baranowska-Rataj, A., \& Nilsson, K. (2020). Not all the same: Swedish teenage mothers' and fathers' selection into early family formation trajectories. Advances in Life Course Research. https://doi.org/10.1016/j.alcr.2020.100326.

Kolk, M. (2014). Understanding transmission of fertility across multiple generations-Socialization or socioeconomics? Research in Social Stratification and Mobility, 35, 89-103.

Kolk, M., Cownden, D., \& Enquist, M. (2014). Correlations in fertility across generations: Can low fertility persist? Proceedings of the Royal Society B-Biological Sciences, 281(1779), 20132561.

Lee, D. (2010). The early socioeconomic effects of teenage childbearing: A propensity score matching approach. Demographic Research, 23, 697-735.

Lesnard, L. (2010). Setting cost in optimal matching to uncover contemporaneous socio-temporal patterns. Sociological Methods and Research, 38, 389-419.

Liefbroer, A. C., \& Elzinga, C. H. (2012). Intergenerational transmission of behavioural patterns: How similar are parents' and children's demographic trajectories? Advances in Life Course Research, 17(1), 1-10.

Manlove, J., Mariner, C., \& Papillo, A. R. (2000). Subsequent fertility among teen mothers: Longitudinal analyses of recent national data. Journal of Marriage and the Family, 62(2), 430-448.

Manning, W. D., \& Cohen, J. A. (2015). Teenage cohabitation, marriage, and childbearing. Population Research and Policy Review, 34(2), 161-177.

McCulloch, A. (2017). Educational aspirations trajectories in England. British Journal of Educational Studies, 65(1), 69-85.

Meade, C. S., Kershaw, T. S., \& Ickovics, J. R. (2008). The intergenerational cycle of teenage motherhood: An ecological approach. Health Psychology, 27(4), 419-429.

Murphy, M. (2013). Cross-national patterns of intergenerational continuities in childbearing in developed countries. Biodemography and Social Biology, 59(2), 101-126.

Murphy, M., \& Knudsen, L. B. (2002). The intergenerational transmission of fertility in contemporary Denmark: The effects of number of siblings (full and half), birth order, and whether male or female. Population Studies-a Journal of Demography, 56(3), 235-248.

Murphy, M., \& Wang, D. (2001). Family-level continuities in childbearing in low-fertility societies. European Journal of Population/revue Européenne De Démographie, 17(1), 75-96.

Oberlander, S. E., Agostini, W. R. M., Houston, A. M., \& Black, M. M. (2010). A seven-year investigation of marital expectations and marriage among urban, low-income, African American adolescent mothers. Journal of Family Psychology, 24(1), 31-40.

OECD. (2016a). "Fertility", in society at a glance 2016: OECD social indicators. Paris: OECD Publishing.

OECD (2016b) Family database. Retrieved from http://www.oecd.org/els/family/database.htm

O'Flaherty, M., Baxter, J., Haynes, M., \& Turrell, G. (2016). The family life course and health: partnership, fertility histories, and later-life physical health trajectories in Australia. Demography, 53(3), 777-804.

Olausson, P. O., Haglund, B., Weitoft, G. R., \& Cnattingius, S. (2001). Teenage childbearing and longterm socioeconomic consequences: a case study in Sweden. Family Planning Perspectives, 70-74

Raab, M., Fasang, A. E., Karhula, A., \& Erola, J. (2014). Sibling similarity in family formation. Demography, 51(6), 2127-2154. 
Reese, B. M., \& Halpern, C. T. (2017). Attachment to Conventional Institutions and Adolescent Rapid Repeat pregnancy: A longitudinal national study among adolescents in the United States. Maternal and Child Health Journal, 21(1), 58-67.

Robette, N., Bry, X., \& Lelièvre, É. (2015). A "global interdependence" approach to multidimensional sequence analysis. Sociological Methodology, 45(1), 1-44. https://doi.org/10.1177/0081175015 570976.

Rook, K. S., Catalano, R., \& Dooley, D. (1989). The timing of major life events: Effects of departing from the social clock. American Journal of Community Psychology, 17(2), 233-258. https://doi.org/ 10.1007/BF00931009

Sassler, S., Cunningham, A., \& Lichter, D. T. (2009). Intergenerational patterns of union formation and relationship quality. Journal of Family Issues, 30(6), 757-786.

Schofer, E., \& Meyer, J. W. (2005). The worldwide expansion of higher education in the twentieth century. American Sociological Review, 70(6), 898-920.

Schoon, I., \& Parsons, S. (2002). Teenage aspirations for future careers and occupational outcomes. Journal of Vocational Behavior, 60(2), 262-288.

Sipsma, H., Biello, K. B., Cole-Lewis, H., \& Kershaw, T. (2010). Like father, like son: The intergenerational cycle of adolescent fatherhood. American Journal of Public Health, 100(3), 517-524.

Stanfors, M., \& Scott, K. (2013). Intergenerational transmission of young motherhood. Evidence from Sweden, 1986-2009. History of the Family, 18(2), 187-208.

Steenhof, L., \& Liefbroer, A. C. (2008). Intergenerational transmission of age at first birth in the Netherlands for birth cohorts born between 1935 and 1984: Evidence from municipal registers. Population Studies, 62(1), 69-84.

SmithBattle, L. (2007). Legacies of advantage and disadvantage: The case of teen mothers. Public Health Nursing, 24(5), 409-420.

Socialstyrelsen (2016) Tonårsaborterna minskar [Teenage abortions on the decline]. Retrieved August 28, 2017, from http://www.socialstyrelsen.se/nyheter/2016/tonarsaborternaminskar

Statens Folkhälsoinstitut (2011). Sexualitet och reproduktiv hälsa [Sexuality and reproductive health]. Kunskapsunderlag för folkhälsopolitisk rapport 2010.

Statistics Sweden (2017) Statistikdatabasen: Medelåldern vid första barnets födelse efter Barnets ordningsnummer, förälder och år [Statistics database: Mean age at first birth per sibship order, parent and year]. Retrieved October 2, 2017

Van Bavel, J., \& Kok, J. (2009). Social control and the intergenerational transmission of age at marriage, rural Holland 1850-1940. Population, 64(2), 379-396.

Wahn, E. H., \& Nissen, E. (2008). Sociodemographic background, lifestyle and psychosocial conditions of Swedish teenage mothers and their perception of health and social support during pregnancy and childbirth. Scandinavian Journal of Public Health, 36(4), 415-423.

Wall-Wieler, E., Roos, L. L., \& Nickel, N. C. (2016). Teenage pregnancy: the impact of maternal adolescent childbearing and older sister's teenage pregnancy on a younger sister. Bmc Pregnancy and Childbirth,

Webbink, D., Martin, N. G., \& Visscher, P. M. (2011). Does teenage childbearing reduce investment in human capital? Journal of Population Economics, 24(2), 701-730.

World Bank (2017) World Development Indicators: Reproductive Health. Retrieved March 3, 2017, from http://wdi.worldbank.org/table/2.17\#

Publisher's Note Springer Nature remains neutral with regard to jurisdictional claims in published maps and institutional affiliations. 